\title{
Physician, heal thy community
}

Clay B. Marsh, MD ${ }^{1}$

\section{Author Affiliations:}

1. West Virginia University, Morgantown, West Virginia

The author has no financial disclosures to declare and no conflicts of interest to report.

\section{Corresponding Author}

Clay B. Marsh, MD

Vice President \& Executive Dean for Health Sciences

West Virginia University

Morgantown, West Virginia

Email: cbmarsh@hsc.wvu.edu 


\section{Abstract}

What if the opioid epidemic and the chronic health problems we encounter in West Virginia and beyond are symptoms of a deeper problem? How can we create healthcare to address the root issues here, and then spread these solutions globally?

\section{Keywords}

opioid, addiction, population health, childhood trauma, resilience, hope, purpose, community health

\section{Physician, Heal Thy Community}

What if the opioid epidemic and the chronic health problems we encounter in West Virginia and beyond are symptoms of a deeper problem? How can we create healthcare to address the root issues here, and then spread these solutions globally?

We struggle to understand how we can improve outcomes and reduce costs of healthcare. To me, the answer is obvious, but perhaps difficult to create - that is, to help our citizens be healthy.

What is health?

I think health is where our biological age (our body's real age) is less than our chronological age (our "number of birthdays" age.) If this is true, biological age is impacted by childhood and adult traumas, as well as our perception of our lives. Great friends, safety, love, purpose and a mindset of abundance are important.

Maybe the risk of poor health and opioid dependency is related to enhanced biological age of our populations and to the lack of resilience to offset these traumas.

Following medical expertise and public or population health is one avenue to reduce biological age. By educating our citizens on the risks of cigarettes, reducing calories, especially the 75 pounds of processed sugar the average American eats annually, and promoting exercise, we can help our population stay younger biologically.

The other keys are human - connections to others that provide love and safety, purpose, and a mindset of abundance and gratitude.

Childhood trauma, outlined in the adverse childhood experience (ACE) survey tested by the Kaiser Family Foundation (http://www.npr.org/sections/health-shots/2015/03/02/387007941/ take-the-ace-quiz-and-learn-what-it-does-and-doesnt-mean), appears to be a risk factor for opioid addiction and all chronic diseases.

This questionnaire consists of 10 questions involving incidents of trauma, neglect and family dysfunction that happen when children are 18 and younger. 
The average score in America has been proffered to have an ACE score of 1. At a score of 4, one's risk of emphysema is elevated 1200x compared with folks who scored 0. Similarly, a score of 6 predicts up to 20 years shorter life-span.

Any score makes one more susceptible to overdose, addiction, and almost every adult chronic disease including cancer, heart disease, obesity, diabetes and high blood pressure.

J.D. Vance, a successful lawyer and the author of Hillbilly Elegy, took the test and found he had an ACE score of 7.

How did he thrive with little disease or addiction burden?

He had people who loved him and created safety for him, mainly his grandmother. This love and safety leads to resilience, which is protective.

This observation takes us back to our purpose - to improve lives and futures through rediscovering what is really important. We must go back to understanding and appreciating the priceless gifts of family, independence, and health. We must go back to our roots as people who evolved and thrived together.

In medicine, our business model has become disconnected from the purpose model. According to Dan Pink, in his great book Drive - The Surprising Truth about What Motivates Us, when the purpose model becomes disengaged from the business model, bad things happen.

We worry more about rankings, listings, awards, papers and scores on exams than about how we change people's lives to those of health, purpose, gratitude, meaning, hope and abundance. We do not recognize the value of building true community at our business places. Instead, we often see people as a necessary commodity.

It is time to change this. It is time to engage in the adventure of our lives and our patients' and communities' lives. The answer to addiction and chronic health problems may be found among our best friends and colleagues, our families, our communities and our struggles.

How do we get back to our purpose and help people be healthy and live fulfilled and meaningful lives?

I think it has to do with identifying the few things that make the most difference.

One of these is rebuilding our communities - at home and in the workplace.

Tom Friedman wrote a great piece recently, A Road Trip Through Rusting and Rising America, in the New York Times. He made the case that the difference between thriving America and failing America is the strength of the communities we live in.

He argues that healthy people make healthy families and healthy families make healthy communities. 
I agree.

The change needs to be bottoms-up: from community members, for their community, reducing isolation and fear.

We have great coalitions in West Virginia working to create resilient communities - from Sustainable Williamson to Try This West Virginia to Celebrate Recovery to The Coalfield Development Corporation to EdVenture to Healthy Harrison and many others. People in West Virginia are creating bright spots through their coalition work.

Healthcare professionals have to play a major part in this transformation. We have to look outside the walls of our hospitals and clinics, and help support the grassroots efforts citizens are creating in our communities. When needed, we have to lead them.

Doctors, nurses, therapists, and others gathered together with citizen activists in June in Buckhannon, as part of the Try This Conference. We learned from one another how to be a part of this movement.

Over 600 people were there, presenting projects from starting running clubs to building baseball fields, and from opening community markets to cleaning up communities.

There were stories of inspired people climbing out of hospital beds to make a ball field for community children, stories of determined people coming out of prison to build gardens, and stories of West Virginians being rescued from drug addiction to help others.

Resonant purpose. Providing hope to others. Hope that West Virginia is rising. Hope in their communities. Hope in a better future.

Together.

We need to spread this to all of West Virginia and beyond. This is manna for us as humans and nourishes the deepest part of us.

This is the basis of resilience at a personal and community level and is the foundation of better health, better lives and better futures.

Like nature, it is an interdependent environment, where everything and everybody ends up contributing to the whole.

This is a way to rebuild and regrow.

Many West Virginians are working every day to build positive futures for our communities, our children, and ourselves. They see a bright future for our people.

So do I. 